\title{
Historia (y memoria) del antifranquismo en el País Vasco ${ }^{1}$
}

\author{
José Antonio PÉRez PÉREZ \\ Universidad del País Vasco \\ joseanperez1965@gmail.com
}

Recibido: 07/05/2013

Aceptado: 10/06/2013

\section{RESUMEN}

Una parte muy importante de la oposición antifranquista que tuvo lugar en el País Vasco fue protagonizada por la izquierda no nacionalista. Sin embargo, la memoria de esa lucha ha quedado diluida en el relato histórico elaborado por el nacionalismo vasco. La desaparición del terrorismo de ETA ha obligado a quienes lo practicaron y apoyaron durante décadas a reforzar su tradicional relato histórico sobre el pasado más reciente. Su objetivo se centra en legitimar su actividad terrorista como una consecuencia inevitable de su lucha contra el franquismo.

Palabras clave: Franquismo, antifranquismo, historia, memoria, País Vasco.

\section{History (and Memory) of the AntiFranco Opposition in the Basque Country}

\begin{abstract}
The non-nationalist left was prominent among the groups that opposed Franco in the Basque Country. However, their fight has almost disappeared from the historical narratives Basque nationalists have formulated over the years. The end of ETA's terrorist actions has forced its practitioners and supporters to reinvigorate traditional historical accounts about their recent past. Their goal was to legitimize terrorist act, presenting them as an inescapable consequence of their fight against Francoism.
\end{abstract}

Key words: Francoism, Anti-Francoism, History, Memory, Basque Country.

\section{Referencia normalizada}

Pérez Pérez, José Antonio (2013) "Historia (y memoria) del antifranquismo en el País Vasco. Una narrativa recurrente tras el final del terrorismo". Cuadernos de Historia Contemporánea, Vol. 35, pp. 41-62.

Sumario: Introducción. 1. Historia del antifranquismo en el País Vasco. 2. Memoria del antifranquismo en el País Vasco. Entre el mito y la impostura. 3. La importancia del relato histórico antifranquista para el nacionalismo radical.

1 Este artículo se inscribe dentro de una de las líneas de trabajo del proyecto de investigación: MINECO HAR-2011-14.409. El proceso de nacionalización española en el País Vasco Contemporáneo (1808-1980): Giro local y conflicto nacional, dirigido por el profesor Luis Castells Arteche. 


\title{
Introducción
}

\begin{abstract}
“... cuando defendimos a los compañeros de ETA, fue desde posiciones humanistas, porque los iban a matar. Y ese humanismo me costó tres años de cárcel y fui allí tan tranquilo. Excepto a ti no se lo he dicho a nadie jamás. Decir que además, quienes fuimos ahí condenados fuimos los de CCOO y los del PCE. Ahí yo no he visto aparecer yo a los nacionalistas ni a nadie por defender a los compañeros de ETA. Ni tampoco a los socialistas. Tampoco. Los que fueron a parar a la cárcel por el juicio de Burgos fueron los comunistas y los de CCOO siendo o no siendo comunistas. Esa es la historia del movimiento obrero en Euskadi, la historia del movimiento obrero revolucionario. Algunos se las dan de revolucionarios porque dicen que han defendido a Euskadi. «Tú no has defendido a Euskadi ni la tercera parte de lo que yo la haya podido defender». Porque defender a Euskadi ¿qué es?. Decir: ¡Gora ETA!. ¡Gora Euskadi!. Defender a Euskadi es defender los intereses de los trabajadores. Porque decir ¡Gora Euskadi! no cuesta nada" 2 .
\end{abstract}

En estos términos se expresaba ya hace algunos años el histórico militante de las Comisiones Obreras de Euskadi, José María Castañares, trabajador metalúrgico de la Sociedad Española de Construcción Naval, nacido en 1932 en el Valle de Trápaga (Bizkaia), juzgado y condenado por el Tribunal de Orden Público. La historia de Castañares -y la percepción que tiene de aquellos años- es compartida por un importante sector de militantes antifranquistas vinculados a la izquierda no nacionalista, forjados en las luchas que tuvieron lugar en el País Vasco a lo largo de las dos últimas décadas de la dictadura franquista.

Al margen de las diferencias que muchos de aquellos militantes que participaron en las protestas mantenían con los métodos, e incluso con los objetivos de los procesados en el juicio de Burgos, lo cierto es que vivieron aquel proceso contra los 16 miembros de ETA como una muestra más de la represión del régimen contra cualquier tipo de oposición. Por ello impulsaron y participaron en las movilizaciones que tuvieron lugar durante el proceso, como un acto de solidaridad con aquellos a los que consideraban compañeros de viaje en la militancia antifranquista.

Sin embargo, después de casi cincuenta años, buena parte de aquellos militantes del movimiento obrero que participaron en las protestas que paralizaron las fábricas desde comienzos de la década de los años sesenta y llenaron la calles -y las cárceles- durante las protestas obreras, incluidas las que se organizaron en solidaridad con los procesados en Burgos, viven hoy con una evidente decepción y con un punto de amargura la apropiación de la memoria del antifranquismo a la que ha procedido el nacionalismo, presentándose ante la sociedad vasca como el gran artífice y protagonista de aquellos años en la lucha contra la dictadura.

\footnotetext{
2 Entrevista realizada a José María Castañares. José Unanue Fundazioa, Fondo de Biografías Obreras.
} 


\section{Historia del antifranquismo en el País Vasco}

Una de las consecuencias más inmediatas de la derrota de la II ${ }^{\mathrm{a}}$ República en la Guerra Civil fue la desmovilización que se produjo entre las fuerzas políticas y sindicales que se habían opuesto a la sublevación militar. Aunque la represión afectó en el País Vasco prácticamente a todas las organizaciones que permanecieron fieles a la legalidad republicana, incluidas las nacionalistas, aquella se cebó con especial dureza en los partidos políticos vinculados a la izquierda y en las organizaciones sindicales de clase. Muchos de sus líderes y militantes más destacados se vieron obligados a partir hacia el exilio. Durante la represión más dura y cruel, la que tuvo lugar durante los primeras semanas de la guerra, los menos afortunados fueron "paseados" y asesinados. Otros muchos fueron detenidos, juzgados, y en algunos casos, ejecutados. Las cárceles se atestaron de presos y los batallones de trabajadores se convirtieron en el destino de cientos de antiguos milicianos y gudaris ${ }^{3}$. Al igual que en el resto de España los locales de los partidos y sindicatos fueron incautados por las nuevas autoridades y liquidados sus órganos de expresión. De este modo cualquier forma de oposición al franquismo quedó prácticamente desmantelada. Como ha apuntado el historiador Pedro Barruso, aunque consiguieron ponerse en marcha algunas acciones de resistencia, prácticamente hasta el final de la II $^{\mathrm{a}}$ Guerra Mundial la oposición al franquismo fue borrada del mapa ${ }^{4}$.

Mientras en el exterior, y especialmente en Francia, donde se trasladó el Gobierno de Euskadi al final de la guerra, la oposición tuvo que hacer frente a los avatares de la ocupación alemana, en el interior su principal objetivo se centró en la mera supervivencia ${ }^{5}$. Tan solo tras la liberación del vecino país la oposición comenzó a dar algunos síntomas de actividad y sobre todo de coordinación, como quedó plasmado en el denominado Pacto de Bayona, suscrito en marzo de 1945 entre los partidos y fuerzas sindicales vascas ${ }^{6}$.

En medio de esta situación los militantes de la izquierda tardaron en dar los primeros pasos hacia una lenta recuperación, que en el caso de los socialistas solo comenzó a concretarse a partir de los congresos del PSOE y la UGT celebrados en Tolouse en 1944. En el interior del País Vasco los miembros de estas organizaciones se refugiaron en las empresas y en el entorno familiar, se mimetizaron con el paisaje social presidido por el miedo y la represión y trataron de sobrevivir. Tan solo la huelga general convocada para el 1 de mayo de 1947 por el Consejo Delegado de Resistencia, formado por STV, UGT y CNT, consiguió remover el

3 El análisis de la represión franquista durante los primeros años de la dictadura no forma parte de los objetivos de este artículo. Un estado de la cuestión en ESPINOSA, Francisco: "Sobre la represión franquista en el País Vasco", en Historia Social, nº 63, 2009.

4 BARRUSO, Pedro: "II República, guerra y primer franquismo en el País Vasco", en BARRUSO, Pedro y LEMA, José Ángel: Historia del País Vasco. Edad Contemporánea. San Sebastián, Hiria, 2005, p. 309.

5 Un minucioso análisis, sobre todo de la oposición desde el exilio, en JIMÉNEZ DE ABERÁSTURI, Juan Carlos: De la derrota a la esperanza (1937-1947), Oñate, IVAP, 1999.

6 El pacto, entre otras cosas, sirvió para reafirmar al Gobierno Vasco como "representación legítima del Pueblo Vasco...", DE PABLO, Santiago, MESS, Ludger, RODRÍGUEZ, José Antonio, El péndulo patriótico. Historia del Partido Nacionalista Vasco II. Madrid, Crítica, 2000, p. 138 
estado de atonía de la oposición contra la dictadura. Una semana más tarde el Gobierno Vasco asumió, a través de una declaración del Lehendakari Agirre, la responsabilidad de la huelga ${ }^{7}$. Aquel conflicto afectó, sobre todo, a las empresas de la Ría de Bilbao y a otras localidades industriales en Guipúzcoa, como Eibar y Elgoibar, donde el movimiento obrero conservaba, pese el miedo, un núcleo de activistas y la memoria de las movilizaciones y conflictos de los años anteriores. Pero aquella acción tan solo consiguió endurecer la represión que se plasmó en forma de detenciones y despidos de cientos de trabajadores.

Durante aquella época el mundo laboral fue uno de los pocos reductos donde, a pesar de la represión y del control social que se estableció desde los primeros años de la dictadura, se daban las circunstancias, las oportunidades y se reunían los condiciones mecesarias para poder organizar y desarrollar una protesta. En 1951 una nueva huelga general alteró la paz social impuesta por el régimen. No fue una protesta totalmente espontánea ni respondió únicamente a las malas condiciones sociales; tuvo también un indudable componente político que siguió en cierto modo la estela del boicot de los tranvías de Barcelona. Dirigentes nacionalistas como Jesús Solaun y Juan Ajuriaguerra venían trabajando en esta línea ${ }^{8}$. Ello no quiere decir que la organización y el desarrollo del conflicto corrieran a cargo únicamente de las organizaciones nacionalistas. Como ocurrió en 1947 en esta nueva huelga participaron antiguos militantes de los sindicatos y partidos de clase (socialistas, comunistas, anarquistas), e incluso algunos elementos desencantados del régimen, y no pocos militantes católicos que poco a poco estaban evolucionando hacia posiciones cada vez más críticas con la dictadura. Sin embargo, ni los trabajadores lograron que se atendieran sus demandas a favor del incremento de los salarios ni por supuesto el Gobierno Vasco consiguió poner en evidencia la debilidad del régimen de Franco, cada vez más afianzado en el poder, que comenzaba a gozar, además, de un evidente respaldo internacional.

En este contexto la recomposición de la oposición política en el interior fue tremendamente complicada y se vio lastrada por la constante persecución de las autoridades franquistas, que se tradujo en numerosas caídas y detenciones. Los comunistas lo vivieron en carne propia en 1948 y los socialistas en 1950 y $1952^{9}$. Pero la situación para los primeros era aún más difícil. Tras el final de la II ${ }^{\mathrm{a}}$ Guerra Mundial y el comienzo de la Guerra Fría, los comunistas se convirtieron también en molestos compañeros de viaje para los partidos republicanos, incluidos aquellos que constituían el gobierno vasco, del que fueron expulsados en 1948. La persecución de las autoridades franquistas y el aislamiento del resto de formaciones políticas llevó al PCE a tratar de abrirse hacia otra serie de sectores más allá del

7 JIMÉNEZ DE ABERASTURI, Juan Carlos y SAN SEBASTIÁN, Koldo (comps.): La huelga general del 1 de mayo de 1947. Artículos y documentos. Centro de documentación de Historia Contemporánea, 5. San Sebastián, Eusko Ikaskuntza, 1991.

8 GONZALEZ PORTILLA, Manuel y GARMENDIA, José María, La posguerra en el País Vasco, San Sebastián, Kriselu, 1988, pp. 259-291.

9 LÓPEZ, Raúl; LOSADA, María y CARNICERO, Carlos: Rojo esperanza. Los socialistas vascos contra el franquismo. Vitoria, Ikusaguer, 2013. PEREZ PÉREZ, José Antonio: “Continuidades y rupturas del obrerismo militante en la Margen Izquierda vizcaína bajo el franquismo", en V Encuentro de investigadores del franquismo. Universidad del Castilla-La Mancha y Fundación Primero de Mayo, Albacete 2003. 
mundo obrero, en un intento por ampliar su capacidad de influencia, su base social y sobre todo, de romper con ese aislamiento al que estaba sometido ${ }^{10}$.

Por lo que concierne a los nacionalistas y especialmente al PNV, su actividad se vio también condicionada por la propia coyuntura internacional y por los avatares de la Guerra Fría ${ }^{11}$. Su aparato de prensa siguió funcionando, especialmente desde latinoamérica, pero su situación en Francia se vio sumamente comprometida cuando el gobierno de este país expulsó al Gobierno Vasco en 1951 de su sede en la Avenida Marceu de París, cediéndosela a las nuevas autoridaes franquistas.

En el interior, la denominada "resistencia vasca" -mucho más mitificada aún que francesa- había realizado algunas acciones más o menos destacables durante los años cuarenta, pero a lo largo de la década de los cincuenta su actividad decayó ostensiblemente. La dirección del PNV se volcó en la reorganización del partido. Para ello recuperó a Juan Ajuriaguerra, refugiado en Francia tras la huelga de 1951 y alejado temporalmente de la dirección del PNV. Sin embargo, todo estaba a punto de cambiar.

La repentina muerte de José Antonio Aguirre en marzo de 1960 significó claramente el final de una etapa para el nacionalismo vasco. Y ello fue así, no sólo porque su sucesor, José María de Leizaola, careciera del carisma del primer lehendakari, sino porque el protagonismo de la lucha de aquellos años pasó a ser detentado por otras nuevas organizaciones.

En julio de 1959, una formación surgida a partir de un grupo de jóvenes denominado EKIN, que había mantenido algunos contactos con el PNV a mediados de los años cincuenta, hizo público un manifiesto político donde abogaba por la defensa de las señas de identidad y los derechos del País Vasco ${ }^{12}$. Se trataba de Euskadi Ta Askatasuna, ETA. Su irrupción en el panorama político puso de manifiesto la existencia de un relevo generacional en el seno del nacionalismo vasco que respondía con su organización a lo que ellos consideraban, según sus propias palabras, como pasividad e ineficacia del PNV y del Gobierno Vasco contra el régimen franquista ${ }^{13}$.

A mediados de los años sesenta ETA se definió como "Movimiento Socialista Vasco de Liberación Nacional", asumió las tesis tercermundistas de los modelos de Argelia, Cuba o Vietnam y la utilización de la lucha armada. Todo ello, -aunque más lo primero que esto último- distanció definitivamente al nacionalismo que

10 En Bilbao se organizaron varias terturlias de carácter artístico y literario, donde participaron tambiénc ciertos sectores de la Asociación Artística Vizcaína y del Instituto de Cultura Hispánica, con participación de militantes del PCE y del FLP entre otros. LASO PRIETO, José María: De Bilbao a Oviedo pasando por el penal de Burgos, Oviedo, Pentalfa, 2002. p. 139.

11 DE PABLO, Santiago, MESS, Ludger, RODRÍGUEZ, José Antonio, El péndulo patriótico. Historia del Partido Nacionalista Vasco II. Madrid, Crítica, 2000, pp. 165-177.

12 GARMENDIA, José María, en ELORZA, Antonio: La Historia de ETA (coord..): Madrid, Temas de hoy, 2000, pp. 92-102. PABLO, Santiago de; MEES, Ludger; y RODRÍGUEZ RANZ, José Antonio: El péndulo...op. cit. 231.

13 GURRUCHAGA, Ander: La refundación del nacionalismo vasco. Universidad del País Vasco, Bilbao, 1989. GURRUCHAGA y Ander: El código nacionalista durante el franquismo. Antrhopos, Barcelona, 1985 y , FERNÁNDEZ Gaizka: Héroes, heterodoxos y traidores. Historia de Euskadiko Ezkerra, 1974-1994, Madrid, Tecnos, 2013.p. 70 yss. 
representaba el PNV de ETA, a quien consideró como un "cáncer marxista" capaz de poner en peligro al Gobierno Vasco y al propio partido.

La irrupción de ETA se produjo en medio de un importante movimiento de recuperación de la cultura vasca y de las señas de identidad de lo vasco, que se percibía amenazado frente al enorme proceso de transformación social que se estaba produciendo. En aquellos momentos el mundo nacionalista asistía atónito a la llegada de decenas de miles de inmigrantes que iban a trasformar la sociedad vasca de los años sesenta, como había ocurrido a finales del siglo XIX, al calor de la primera industrialización. El crecimiento incontrolado de las ciudades, la extensión del espacio industrial, el chabolismo, los profundos cambios que se produjeron en el ámbito demográfico o el estallido de las huelgas que anunciaban la reconstrucción del nuevo movimiento obrero, fueron tan solo algunos de los síntomas de esa transformación que estaba cambiando el País Vasco. En este contexto la difusión de obras como Vasconia de Federico Krutwig (1963), fue decisiva en la interiorización de una determinada manera de concebir lo vasco desde una perspectiva etnicista y excluyente, donde se expresaba de forma clara y contundente el recurso a la violencia revolucionaria como un medio más de lucha ${ }^{14}$. El mundo cultural vasco vivió una enorme convulsión, donde tanto el nacionalismo radical como el izquierdismo sacudieron los valores tradicionales sobre los que se sustentaba, convirtiéndolo en gran medida en otro frente de oposición.

Hasta ese momento ETA había limitado sus acciones a la propaganda y a algunos atentados contra determinados objetivos de carácter simbólico, como el intento de descarrilamiento de un tren cargado con excombatientes en $1961^{15}$. Pero a partir de la V Asamblea, en 1966, la organización acentuó sus acciones violentas. Fue precisamente durante los años siguientes cuando comenzó a manifestarse de forma más clara su activismo a través de la puesta en práctica del llamado principio de la espiral acción-reacción.

La celebración del Aberri Eguna en la primavera de 1968 terminó con la capital guipuzcoana convertida en un auténtico campo de batalla. Algunos de los testigos que vivieron aquella época -desde el interior o desde la periferia de la organización ETA-, interpretan el incremento de la tensión previa a los "primeros muertos" de la organización como un proceso cuasi inevitable que terminó desembocando en los conocidos acontecimientos del verano de aquel año ${ }^{16}$. El primer atentado mortal de ETA, cometido el siete de junio de 1968, ha dado lugar a una verdadera leyenda en torno a las circunstancias que rodearon aquel acto y a quienes fueron sus protagonistas; el cabo de la Guardia Civil, José Pardines y el joven dirigente de ETA, Txabi Etxebarrieta. La muerte del primero abriría una larga lista de víctimas de una organización que marcaría la historia del País Vasco durante cuatro décadas. Pero

14 MORÁN, Gregorio: Los españoles que dejaron de serlo. Barcelona, Planeta, 2003, pp. 332-337,. Una visión un tanto matizada era la de Mario Onaindia, según JUARISTI, Jon: Cambio de destino. Barcelona, Seix Barral, 2006. Véase también FERNÁNDEZ SOLDEVILLA, Gaizka y LÓPEZ ROMO, Raúl: Sangre, votos, manifestaciones: ETA y el nacionalismo radical vasco: 1958-2011. Ed. Tecnos, Madrid, 2012, pp. 264 y ss.

15 DOMÍNGUEZ, Florencio: ETA: Estrategia organizativa y actuaciones, 1978-1992. Bilbao, UPV/ EHU, 1998. pp. 220 y 221. Véanse también a este respecto MUÑóZ ALONSO, Alejandro. El terrorismo en España. Barcelona, Planeta, 1992, p. 13, y Gaizka: Héroes, heterodoxos y traidores. Historia de Euskadiko Ezkerra, 1974-1994, Madrid, Tecnos, 2013.p. 70 y ss.

16 Véase MORÁN, Gregorio: Los españoles... op. cit. p. 22. 
la muerte de Xabi fue mucho más. Provocó una enorme conmoción en el ámbito nacionalista y, en general, en todo aquel heterogéneo mundo que se movía dentro del antifranquismo en el País Vasco y proporcionó a ETA su primer mártir ${ }^{17}$.

Apenas dos meses más tarde, el 2 de agosto, ETA llevó a cabo su primer asesinato planificado, el del comisario Melitón Manzanas, antiguo colaborador de la Gestapo y cabeza visible de la represión franquista en Guipúzcoa, por cuyas manos habían pasado un largo número de dirigentes y militantes de la oposición antifranquista desde la posguerra. Se trató de un objetivo cuidadosamente elegido. El miembro de la temida Brigada Político Social encarnaba en sí mismo la representación más cruel de la represión franquista en Guipúzcoa y su asesinato fue recibido con satisfacción entre amplios sectores de la sociedad vasca ${ }^{18}$.

La respuesta del régimen fue tan contundente como indiscriminada, dando lugar a una larga serie de detenciones donde los malos tratos y las torturas se practicaron de forma generalizada ${ }^{19}$. Todo ello provocó una oleada de solidaridad con los afectados y atrajo hacia las filas de la nueva organización a un gran número de jóvenes. El estado de excepción decretado tras aquel atentado abrió un ciclo de conflictos, detenciones y exilios que contribuyó aún más a generalizar el clima de rechazo contra las Fuerzas de Seguridad del Estado.

Este incremento de la tensión política y social culminó en diciembre de 1970 con la celebración del Juicio de Burgos contra 16 miembros de ETA. Sobre ellos pesaba la acusación de pertenecer a la organización armada y ser responsables de los asesinatos cometidos hasta ese momento por ella y de otros delitos, como atentados y diversos robos. La movilización de protesta contra este juicio no solo afectó al País Vasco. Se extendió por el resto de España, sobre todo entre los círculos políticos, intelectuales y obreros de la oposición antifranquista. El proceso tuvo un importante eco internacional, especialmente tras el secuestro y posterior liberación del cónsul honorario alemán Eugen Beihl Shaeffer. La represión contra las movilizaciones de protesta contribuyó aún más a extender entre amplias capas sociales la solidaridad hacia los condenados, y por extensión, hacia la causa defendida por la organización ETA.

Tras un periodo de reflujo de la actividad armada ETA incrementó y diversificó sus acciones a lo largo de 1972, mediante secuestros de empresarios, atracos y voladuras de edificios y monumentos con un gran contenido simbólico. Sus acciones fueron duramente respondidas por la policía y dejaron un reguero de muertes de militantes de esta organización tras varios enfrentamientos y persecuciones.

17 Sobre el tema de la creación del mito de Txabi Etxebarrieta y la peculiar martiriología del abertzalismo radical véase JUARISTI LINACERO, Jon: Sacra Némesis. Nuevas historias de nacionalistas vascos. Madrid, Espasa, 1999, pp. 105-139 y sobre Argala, CASQUETE, Jesús: "La apoteosis del héroe-mártir en el nacionalismo vasco radical" en Cuadrenos Bakeaz n 81, 2007.

18 Resulta significativo que de las más de cien entrevistas realizadas durante los últimos años a militantes antifranquistas de todas las tendencias muy pocos sintieran el asesinato de Manzanas. Incluso los comunistas, que más tarde se pondrían al frente de las manifestaciones contra ETA, celebraron aquel atentado. Mundo obrero lo calificó como un "acto justiciero". Véase FERNÁNDEZ SOLDEVILLA, Gaizka: Héroes, heterodoxos y traidores...op. cit. p. 63.

19 A lo largo de 1968 se practicaron 434 detenciones con un resultado de 189 encarcelados, 75 deportados y 38 exiliados. En 1969 la cifra de detenidos sin juicio llegaría a los 1953, Véase GARMENDIA; José María: Historia de ETA, Donostia, Haranburu Editor, 1995. 
Pero sin duda alguna fue el atentado contra el presidente del Gobierno Luís Carrero Blanco, en diciembre de 1973, el que provocó una mayor conmoción dentro de la sociedad vasca y española. Tal y como se ha afirmado, este atentado fue el más espectacular y "rentable" de la organización, al menos hacia el exterior. El historiador José María Garmendia, un excelente conocedor de la realidad interna de ETA durante aquella época, que fue además miembro de aquella organización hasta 1974, cuando se integró con otros muchos militantes en el PCE-EPK, ha escrito que con el proceso de Burgos nació "una nueva generación de militantes dispuestos a lo que hiciera falta, el atentado contra Carrero Blanco colmó las mejores expectativas, con lo que el militarismo se situó fuera de todo debate (...)"20.

Sin embargo, no era lo mismo atentar contra el presidente del Gobierno, un Almirante que había hecho la guerra con Franco y que se había destacado por su virulencia contra la oposición antifranquista ${ }^{21}$, que hacerlo de forma indiscriminada como ocurrió poco más tarde. No lo era para quienes habían observado con simpatía la irrupción de este movimiento; pero tampoco lo era para muchos militantes dentro de las filas de la propia organización. Las tensiones internas acumuladas durante los últimos años se desataron tras el atentado del 13 de septiembre de 1974, cuando ETA-que nunca reivindicó el atentado- colocó una bomba en la Cafetería Rolando de Madrid y asesinó a trece personas. Aunque la escisión entre ETA militar y ETA político militar no fue el resultado del cuestionamiento de la violencia armada, sino sobre todo el desencuentro sobre las diferentes perspectivas acerca de la estrategia política más adecuada, lo cierto es que el atentado de la calle Correo tuvo un peso específico en esta ruptura ${ }^{22}$.

El estado de excepción de abril de $1975^{23}$ y la ley antiterrorista del 26 de agosto de ese año, tan sólo sirvieron para elevar aún más la tensión que se desbordó con los procesos de ese verano y la ejecución de los militantes de ETA Juan Paredes "Txiki" y Ángel Otaegui y los del Frente Revolucionario Antifascista y Patriota (FRAP). El fusilamiento tras un juicio sumarísimo plagado de irregularidades procesales elevó la categoría de los ajusticiados, dotándoles del rango militar que la propia ETA reclamaba para sus miembros. El 27 de octubre se convirtió desde entonces en el Gudari Eguna, todo un regalo para aquellos que se presentaban como sucesores de los soldados que formaban parte del ejército vasco durante la guerra civil.

Ciertamente, la aparición del fenómeno de ETA provocó una enorme conmoción en el mundo nacionalista y nuevos problemas al PNV. Pero a pesar de que la represión facilitó durante los primeros años la cohesión entre quienes compartían un mismo código identitario y formaban parte de una misma comunidad, las diferencias se tornaron en enfrentamientos. Además de la inspiración marxista que rezumaba la nueva organización, en el horizonte más inmediato se dibujaba una confrontación entre dos estrategias

20 GARMENDIA, Jose María: "ETA: Nacimiento, desarrollo ... op. cit. p. 168.

21 YSÀS, Pere: Disidencia y subversión: La lucha del régimen franquista por su supervivencia. (19601975), Barcelona, Crítica, 2004, pp. 139-149.

22 GARMENDIA, José María: Historia de ETA... op. cit. p. 168. Para la evolución posterior de ETA pm y de Euskadiko Ezkerra, véase FERNÁNDEZ, Gaizka: Héroes, heterodoxos y traidores.... op. cit.

23 En algunas zonas concretas del País Vasco el estado de excepción fue especialmente duro, llegando a constituir en un verdadero estado de sitio, como ocurrió en Gernika, donde la Guardia Civil, comandada por el Capitán Hidalgo llevó a cabo una represión brutal durante aquella época. Véase a este respecto ETXANIZ, José Ángel: «El último estado de excepción en Gernika-Lumo». Aldaba, nº 133, Gernika, 2005. 
muy diferentes. Por un lado el frente nacional defendido por ETA, y por el otro la unión vasca, integrada por nacionalistas, republicanos y socialistas por la que abogaba el PNV. Pero, sobre todo, las diferencias entre ambos proyectos ponían de relieve una lucha abierta por el liderazgo político del nacionalismo vasco ${ }^{24}$.

Durante todo este periodo que definió el tramo final del franquismo el PNV siguió trabajando en el exterior, participando activamente en diferentes foros junto con otras organizaciones y elementos de la oposición socialista, liberal y democristiana, como ocurrió en el coloquio de Munich de 1962, en el marco del IV congreso del Movimiento Europeo. Sin embargo, su participación activa en la oposición del interior fue mucho más discreta y se limitó a la convocatoria de la celebración del Aberri Eguna y a otra serie de actos simbólicos y muy puntuales.

A lo largo de los últimos años de la dictadura el PNV incrementó su participación y presencia pública en diferentes plataformas conjuntas, como en el caso de la Junta Democrática creada en 1974, donde mantuvo contactos permanentes, aunque con una representación circunscrita al plano personal, en la Plataforma de Convergencia Democrática en 1975 y el Consejo Federal Español del Movimiento Europeo. En definitiva, el partido se preparaba para los nuevos tiempos en todos los ámbitos y no le costó sortear la dura represión que sufrían otros sectores políticos mucho más comprometidos en el interior.

Pero la oposición en el País Vasco durante los años sesenta y setenta no se limitó a la actividad que desarrolló ETA, ni por supuesto el PNV. La izquierda no nacionalista jugó un papel determinante durante esta época, aunque, como veremos más adelante, su historia se haya difuminado de la "memoria colectiva". Desde 1953 los Comités Centrales del PSOE y la UGT en el País Vasco constituían una especie de dirección clandestina de los socialistas. Sin embargo, las tentativas del vitoriano Antonio Amat y del vizcaíno Ramón Rubial por consolidar una dirección central a partir de las estructuras del Norte no terminaron por cuajar durante el periodo de 1953 a 1967. A partir de esta fecha Rubial se vio respaldado por la incorporación de una nueva generación de militantes que no estaban marcados directamente por la experiencia de la República y la Guerra Civil, como los ya citados Nicolás Redondo, Eduardo López Albizu o del abogado donostiarra Enrique Múgica. Los primeros, trabajadores de la Naval en la Margen Izquierda del Nervión, representaban la tradición obrerista, mientras que Enrique Múgica, que anteriormente había sido miembro del PCE, y otros de su generación, procedían de otra cultura política no directamente vinculada al mundo obrero ${ }^{25}$.

Desde finales de la década de los sesenta, los dirigentes de las federaciones vascas se centraron en la reestructuración de la organización clandestina, constituyendo agrupaciones activas y centralizadas. La radicalización de las vanguardias y la crispación social que se respiraba en el País Vasco afectó de un modo especial a los dirigentes guipuzcoanos y vizcaínos. El traslado de la dirección real de los socialistas del exterior al interior fue complicado, sobre todo para aquella generación de la guerra y el exilio. Este proceso, complicado y traumático en muchos casos, se fue acelerando y los socialistas vascos -renovadores-, encabezados por Redondo, Múgica y López se fueron

24 PABLO, Santiago, MEES, Ludger y RODRÍGUEZ, José Antonio: op. cit. pp. 300-324.

25 LÓPEZ, Raúl, LOSADA, María y CARNICERO, Carlos: Rojo esperanza... op. cit. pp. 127 y ss. 
incorporando en noviembre de 1970 a la Comisión Permanente, es decir, la "Comisión Ejecutiva en el Interior". Las diferencias que separaban a los dirigentes del interior, más jóvenes y apegados a la realidad del país, frente a los históricos del socialismo español en el exilio, encabezados representados por Rodolfo Llopis, se pusieron claramente de relieve con la celebración de dos congresos en agosto y diciembre de 1972 y con la escisión del PSOE histórico. En realidad, el Congreso de Suresnes de 1974, que encumbró a Felipe González como máximo líder del partido y completó el traslado de la dirección al interior de España, fue la escenificación de todo un proceso que arrancó desde finales de los años sesenta, en el que los socialistas vascos tuvieron un protagonismo decisivo ${ }^{26}$.

Sin embargo, tampoco fueron los socialistas, más allá de excepciones puntuales como las que se han señalado en la figura de algunos de sus más destacados sindicalistas, quienes llevaron el peso del antifranquismo en el País Vasco dentro de la izquierda no nacionalista, ni por supuesto, quienes soportaron la represión más dura. El estallido de los conflictos de 1962 hizo que la dirección de los comunistas enviase al interior al máximo dirigente del PC de Euskadi, Ramón Ormazabal. Su presencia fue detectada por la Brigada Política y Social y desencadenó en junio de aquel año una de las caídas más importantes de la época ${ }^{27}$. El Consejo de Guerra que juzgó a este grupo en 1963 tuvo un eco muy importante y fue utilizado por Ormazabal para difundir la nueva línea política favorable a la Política de Reconciliación Nacional adoptada por el PCE unos años antes ${ }^{28}$.

El encarcelamiento de este dirigente constituyó un nuevo golpe para los comunistas vascos, pero la implicación de líderes del movimiento obrero como Tomás Tueros o David Morín relanzó durante aquella época la presencia del partido en el interior. Aquel periodo, que arrancó a comienzos de la década de los años sesenta y que culminó con el final de la dictadura, estuvo marcado por la reorganización del movimiento obrero y la extensión de una conflictividad desconocida desde los tiempos de la II ${ }^{a}$ República. Tras la huelga de la primavera de 1962, que siguió la estela de las huelgas asturianas, se produjo en el País Vasco una dura represión, pero también fue el origen de la reorganización del movimiento obrero. La constitución de la primera Comisión Obrera Provincial de Vizcaya en la primavera de 1963, con la participación de militantes católicos de la HOAC y la JOC junto a destacados militantes comunistas, marcó un punto de inflexión en este proceso que culminaría en la consolidación de las CCOO de Euskadi, protagonista fundamental para comprender la importancia del antifranquismo en el País Vasco $^{29}$.

26 MATEOS, Abdón: El PSOE contra Franco. Continuidad y ruptura en el socialismo español, 19531974, Madrid, Fundación Pablo Iglesias, 1993, p. 413 y MATEOS, Abdón: Exilio y clandestinidad. La reconstrucción de la UGT, 1939-1977, Madrid, Uned, 2002, 68-69. AROCA, Manuela: El sindicalismo socialista en Euskadi (1947-1985). De la militancia clandestina a la reconversión industrial. Madrid, Biblioteca Nueva, 2013.

27 Junto con Ramón Ormazabal fueron detenidos, entre otros, los hermanos Ibarrola, Enrique Múgica, Antonio Jiménez Pericas, Vidal de Nicolás o Maria Dapena. Véase a este respecto IBÁÑEZ ORTEGA, Norberto y PÉREZ PÉREZ, José Antonio: Ramón Ormazabal: Biografia de un comunista vasco (1910-1982), Madrid, Latorre Literaria, 2005.

28 Ibídem.

29 Hay que destacar en este caso la importante participación de católicos en las primeras Comisiones Obreras de Euskadi. En la COPV cuatro de los cinco representantes pertenecían a los grupos católicos. 
El propio argumento que defendió el Ministerio de Trabajo a principios de los años 70 explicaba de una manera tan sencilla cómo contundente como se fueron politizando los conflictos laborales desde la década anterior: "Un conflicto laboral es siempre un problema político y de orden público". Ciertamente, aunque la mayor parte de aquellos conflictos de trabajo que surgieron tras la promulgación de la ley de Convenios Colectivos aprobada en 1958 tuvo, generalmente, un origen estrictamente laboral, terminaron por tener unas consecuencias políticas y se convirtieron en una expresión -una de las más importantes-, del antifranquismo. Así ocurrió con todas aquellas huelgas que comenzaron a generalizarse desde principios de los años sesenta y que tuvieron en el País Vasco uno de sus epicentros más importantes. Algunos de estos conflictos, como el surgido en la empresa de Bandas de Laminación de Echévarri en noviembre de 1966 por motivo estrictamente laborales, constituyeron un ejemplo de este proceso. Tras 163 días de huelga, donde los trabajadores recurrieron a todo tipo de movilizaciones, las autoridades se vieron superadas por la situación y terminaron por imponer un estado de excepción ${ }^{30}$.

Pero en otras ocasiones las huelgas sí tuvieron un origen claramente político, como ocurrió por ejemplo en aquellas protestas que se convocaron en diciembre de 1970 en solidaridad con los miembros de ETA procesados en Burgos, donde los miembros del PCE de Euskadi y de las CCOO volvieron a tener un protagonismo determinante que llevó a muchos de ellos a ser detenidos, juzgados y condenados.

A partir de comienzos de la década de los años setenta, la organización comunista trató de ampliar su base social aplicando en Euskadi la denominada política del "Pacto para la libertad", en un intento por salir del "guetto" del movimiento obrero tradicional. Todo ello coincidió con la evolución de la organización ETA. Los contactos entre ésta y el PCE se formalizaron en un documento conjunto de denuncia contra la represión firmado en noviembre de 1970 y poco más tarde, entre 1973 y 1974, se produjo la incorporación de un importante grupo de militantes de ETA procedentes de la escisión entre los conocidos como mayos y minos $^{31}$.

La oposición organizada dentro del mundo de la izquierda en el País Vasco no terminaba en el PSOE y ni el PCE. A partir de las huelgas de la universidad de 1956 fueron surgiendo nuevas formaciones. Una de ellas fue el Frente de Liberación Popular, el Felipe (FLP), que en Euskadi adoptó el nombre de Euskadiko Sozialisten Batasuna, (ESBA), donde contaron con la presencia de líderes como el abogado donostiarra José Ramón Recalde. Dentro del mundo católico del que procedían muchos miembros del Felipe, también surgieron organizaciones que se acercaron al movimiento obrero al calor del debate que surgió en torno al Concilio Vaticano II, dando

30 Para todo este proceso véase PÉREZ PÉREZ, José Antonio: Los años del acero. La transformación del mundo laboral en el área industrial del Gran Bilbao, 1958-1977. Trabajadores, convenios y conflictos. Madrid, Biblioteca Nueva, 2001. pp. 293-304.

31 De estos últimos procedieron algunos hombres fundamentales en la evolución posterior del PCE-EPK, como Javier Ardanza, José María Garmendia o Juan Mari Jáuregui. Véase GARMENDIA, José María: Historia del ETA... op. cit. 1995, ETXANIZ, José Ángel: "La revitalización del Partido Comunista de Euskadi, 19701975. El ingreso de ETA VI Asamblea (Minos)", en BUENO, Manuel, HINOJOSA, José y GARCÍA, Carmen: Primer Congreso de Historia del PCE (1920-1977), Oviedo, 2004, pp. 313-334. 
lugar, entre otras, a la Acción Sindical de Trabajadores (AST) ${ }^{32}$. En el País Vasco su núcleo se situó en la escuelas sociales de los jesuitas de Vitoria y en 1970 se transformó en la ORT, que tuvo su centro más importante en Navarra.

En otros casos, las organizaciones que se fueron situando en la extrema izquierda surgieron de la propia evolución y de las escisiones de ETA, como sucedió a partir de 1967, cuando Patxi Iturrioz y Eugenio del Río crearon ETA berri. Con el tiempo esta organización se transformó en el Movimiento Comunista Vasco (Komunistak), en la órbita del maoísmo y a partir de 1971 el grupo se unió a otros colectivos similares del resto de España, dando lugar al $\mathrm{MCE}^{33}$.

Como ya se ha apuntado, durante el juicio de Burgos, o coincidiendo con el mismo, se produjo una fuerte discusión interna que dejó a ETA dividida en cuatro facciones: por un lado, la nueva dirección que pretendía crear un partido leninista y las Células Rojas, con una ideología similar pero con fuertes discrepancias personales entre ambos sectores; por el otro estaba el sector más abertzale y el anticolonialista representado por el frente militar, partidario del ultranacionalismo y del terrorismo. Posteriormente, el julio de 1972, ETA VI se dividió, como ya se ha apuntado, entre los mayoritarios (mayos) y minoritarios (minos) y unos meses más tarde los mayos se unieron a la Liga Comunista Revolucionaria, dando lugar a ETA VI-LCR, que se convirtió más tarde en $\mathrm{LCR}^{34}$.

Todos estos grupos y otros más que fueron surgiendo en el final del franquismo tuvieron una presencia importante en los movimientos sociales que crecieron al calor de las protestas del final de la dictadura. Especialmente importante fue su papel en el sindicalismo vasco y más en concreto en las CCOO, donde disputaron al PCE-EPK su hegemonía en algunos momentos, e incluso llegaron a liderar huelgas tan importantes como la del 11 de diciembre de 1974, en una importante protesta contra la carestía de la vida. También fue importante su presencia en el movimiento estudiantil y en el movimiento vecinal que surgió a raíz de los enormes problemas sociales que provocó la especulación incontrolada y el desarrollismo de los años sesenta y setenta. Este proceso convirtió a muchos de aquellos barrios de nueva creación en un núcleo de actividad social y política, donde la presencia de los grupos católicos, del PCEEPK y de las organizaciones de la extrema izquierda, fue mayoritaria e imprimió un carácter cada vez más político a muchas de aquellas reclamaciones que en principio tenían una raíz social ${ }^{35}$.

En todo este proceso que se desató desde la década de los años sesenta el mundo católico jugó un papel nada desdeñable, y no solo aquel que favoreció la evolución de

32 No fueron las únicas organizaciones sindicales vinculadas al mundo católico. A principios de la década de los sesenta había surgido la Unión Sindical Obrera (USO) donde fueron recalando numerosos católicos tras su salida de las CCOO en 1967, incluidos algunos de sus fundadores.

33 Sobre la evolución de la extrema izquierda en Euskadi, su relación con el abertzalismo radical y con la violencia véase FERNÁNDEZ, Gaizka y LÓPEZ, Raúl: Sangre, votos... op. cit. pp. 293 y ss.

34 Un grupúsculo de este partido se escindió para formar la LC (Liga Comunista) mientras la mayor parte de los minos, entre los que destacaba Roberto Lertxundi, terminó por integrarse en el PCE-EPK a comienzos de 1974. Véase a este respecto ETXÁNIZ, José Ángel: “La revitalización... op. cit. y GARMENDIA, José María. Historia de ETA...op. cit. pp. 462-492.

35 Véase a este respecto MOLINERO, Carme e YSÀS, Pere: "Movimientos sociales y actitudes políticas en la crisis del franquismo", en Historia Contemporánea, 8, 1992, p. 275 
la Acción Católica a través de la HOAC y la JOC que representó al sector más activo y comprometido en la lucha antifranquista. Desde comienzos de la década de los años sesenta un importante sector de la iglesia vasca comenzó a manifestarse a favor de "los derechos del pueblo vasco" y de los trabajadores. La carta de los 339 curas vascos de 1960 fue la expresión más palpable de este cambio que se estaba produciendo. Más tarde vendría el procesamiento de un número importante de sacerdotes por el Tribunal de Orden Público y otras acciones, como la ocupación de la Curia, el encierro del seminario de Derio o la formación en 1968 del grupo Gogor, compuesto por sacerdotes abertzales próximos a las tesis de ETA. A principios de la década de los años setenta la grieta entre la dictadura y la iglesia fue haciéndose más profunda en el País Vasco y alcanzó a las más altas esferas. La actitud del obispo Cirarda negándose a conmemorar en 1970 la toma de Bilbao por las tropas de Franco con la celebración de una misa ensanchó esa fecha, y su firma junto al obispo de San Sebastián, en una carta pastoral sobre el Proceso de Burgos ensancharon esa brecha ${ }^{36}$.

La tensión y los enfrentamientos adquirieron más envergadura y el régimen de Franco se vio obligado a habilitar una cárcel en Zamora para los clérigos condenados a penas de prisión, donde se produjeron motines y varias huelgas de hambre. En febrero de 1974 el obispo de Bilbao Antonio Añoveros envió a todas las parroquias vizcaínas un escrito para que fuera leído como homilía. En el texto se defendía el "derecho del pueblo vasco a conservar su propia identidad" que "tropezaba con serios obstáculos para disfrutar de ese derecho". La homilía desató la ira del Gobierno que decretó el arresto domiciliario del prelado y pidió a la Santa Sede que llamara al obispo a Roma. Incluso se valoró la posibilidad de expulsar a Añoveros de España, pero la amenaza de excomunión del Gobierno por parte de la Conferencia Episcopal evitó la medida contra el obispo. Arias Navarro, sucesor de Carrero Blanco, llegó a pensar en romper relaciones con el Vaticano y denunciar el Concordato. Las amenazas no se cumplieron pero el enfrentamiento puso de relieve hasta que punto había llegado el desencuentro entre la jerarquía de la Iglesia y el régimen al final de la dictadura.

\section{Memoria del antifranquismo en el País Vasco: entre el mito y la impostura}

El fenómeno no es nuevo ni tampoco es exclusivamente vasco. La pérdida de peso de lo que podríamos llamar, aunque con muchos matices, la memoria colectiva del antifranquismo o la lectura sesgada de aquella época en el País Vasco, no es achacable únicamente a una determinada interpretación del reciente pasado por parte del nacionalismo. La propia consideración e interpretación del antifranquismo que se produjo durante la transición en términos generales ha contribuido a ello. Algo parecido, aunque con otras connotaciones y protagonistas ocurrió en Catalunya, donde para algunos autores la llegada de la democracia habría representado también la deslegitimación del antifranquismo catalán, algo cuya principal responsabilidad recaería en

36 Para un seguimiento de todo este proceso véase: BARROSO, A.: Sacerdotes bajo la atenta mirada del régimen franquista. Los conflictos sociopolíticos de la Iglesia en el País Vasco desde 1960 a 1975 . Instituto Diocesano de Teología y Pastoral Bilbao. Bilbao, Desclée De Brouwer. 1996 
el nacionalismo "pujolista". ${ }^{37}$ Como recuerda Javier Tebar en un trabajo de reciente aparición, el también historiador y sociólogo catalán Josep María Colomer “diseccionaba de manera polémica el antifranquismo catalán, subrayando su potencial y los límites de su actuación, pero sobre todo exponiendo crudamente la progresiva superación y el carácter contradictorio del patrimonio político, moral e ideológico que representó" 38 . Al margen de los importantes matices que puedan introducirse sobre esta cuestión, lo cierto es que, como afirma el propio Tebar "el antifranquismo no constituyó en nuestro país un referente legitimador de nuestra actual democracia, al menos no del mismo modo en que lo fue el antifascismo para la democracia italiana, alemana o francesa después de la Segunda Guerra Mundial. En España ese elemento legitimador se identificaría con el proceso de la transición política hacia la democracia liberal parlamentaria”. Pero a diferencia de aquellos otros países, en España las actitudes y comportamientos de los principales artífices de la democracia en nuestro país no parecen contar con suficiente relieve. ${ }^{39}$ Por el contrario, continúa Tebar, "es un "tiempo" determinado, preciso, dentro del proceso de democratización del país el que se toma como elemento legitimador, y el que actuaría, de manera simultánea, como referente auto-legitimante de los actores políticos que participaron en el propio proceso de tránsito de un régimen autoritario a uno democrático" 40.

Compartimos en general esta visión. Sin embargo, en el País Vasco donde la transición tuvo un desarrollo anómalo con respecto al resto de España ${ }^{41}$, esta circunstancia es más que discutible y lo es por diferentes motivos. En primer lugar porque mientras el nacionalismo moderado que representaba PNV, el centro derecha de la UCD, la izquierda (PSE, EPK e incluso EE) y los sindicatos mayoritarios en aquellos momentos apoyaron sin ambages el proyecto democrático, renunciando en algunos casos a algunas de sus reivindicaciones históricas, la extrema izquierda, que pronto sería residual pero muy activa, y el nacionalismo radical, nucleado en torno a ETA-m y su entorno, representado por Herri Batasuna, cuestionaron y rechazaron todos y cada uno de los pasos que se dieron a favor del sistema democrático ${ }^{42}$.

37 LORÉS, Jaume, La transició a Catalunya (1977-1984). El pujolisme i els altres. Barcelona: Empúries, 1985, p. 121, pp. 107-108, cit. por TEBAR, Javier: "La resistencia ordinaria durante el tardofranquismo" en TEBAR, Javier (ed.): Resistencia ordinaria. La militancia y el Antifranquismo Catalán ante el Tribunal de Orden Público (1963-1977). Valencia, Universidad de Valencia, 2012.

38 COLOMER, Josep Maria, La ideologia de l'antifranquisme. Barcelona: Edicions 62, 1985, p. 15 y p. 21.

39 FOWERAKER, Joe, Los verdaderos artifices de la democracia en España. Madrid: Arias Montano, 1990, pp. 22-23; BALFORD, Sebastian, La dictadura, los trabajadores y la ciudad. El movimiento obrero en el área metropolitana de Barcelona (1939-1988). Ed. Alfons El Magnànim. València, 1994, pp. 9-10.

40 GALLEGO, Ferran, "La genealogía de la transició política espanyola (1973-1977)”, Segle XX, revista catalana d'història núm. 2 (2009), pp. 123-124.

41 RIVERA, Antonio: “La transición en el País Vasco. Un caso particular”, en Ugarte, Javier: La transición en el País Vasco y España, Bilbao, UPV/EHU, 1996.

42 Aunque dentro de la extrema izquierda también hubo posiciones diferenciadas con respecto a la violencia. Mientras la Liga Comunista Revolucionaria (en el País Vasco y Navarra Liga Komunista Irazultzailea, LKI) y el Movimiento Comunista de Euskadi (Euskadiko Mogimendu Komunista, EMK) mantuvieron una posición condescendiente con el terrorismo durante años, otros grupos como la Organización Revolucionaria de Trabajadores (ORT) y el Partido del Trabajo de España (PTE), posteriormente ambos unificados en el Partido de los Trabajadores de España (PTE-ORT), aceptaron la vía institucional y asumieron una crítica activa del terrorismo de ETA. Véase a este respecto FERNÁNDEZ SOLDEVILLA, Gaizka y LÓPEZ ROMO, Raúl: Sangre, votos... op. cit. pp. 293 y ss. 
Como hemos visto, durante los últimos años de la dictadura la oposición al régimen en el País Vasco fue muy activa, pero buena parte de las organizaciones políticas de la izquierda, incluidas las abertzales más radicales, rechazaban el modelo democrático liberal. Prácticamente todas las organizaciones de uno y otro signo, desde las más moderadas a los grupos más extremistas de corte marxista, maoísta o trostkista, reivindicaban la democracia, pero esta quedaba incluida -y casi diluida- dentro de un amplio paquete de reivindicaciones que abarcaba desde "los derechos del pueblo vasco" hasta "la toma del poder por la clase obrera", sin que la exigencia de un sistema democrático apareciera como un objetivo específico ni prioritario ${ }^{43}$. En realidad, muchas de estas organizaciones, influidas por los procesos de liberación nacional que se habían producido en el ámbito internacional durante las últimas décadas, pero también por cierta cultura política que provenía de antes de la época republicana, concebían la democracia desde una perspectiva puramente instrumental. Desde esta perspectiva, la reivindicación de una democracia constituía solo un medio para alcanzar los verdaderos objetivos: la liberación nacional, la liberación social, o ambas cosas a la vez. Las consecuencias de esta situación marcarían los comportamientos políticos durante los convulsos años de la transición. La democracia no se concebía para muchos sectores como la forma política capaz de expresar la voluntad ciudadana, sino como un medio para desarrollar sus respectivos idearios políticos. Esta perspectiva alimentó los maximalismos en aquellas formaciones que proponían cambios inmediatos, contundentes e irreversibles, difícilmente compatibles con los criterios de una democracia occidental. El historiador Fernando Molina ha apuntado en este sentido lo siguiente:

"Este Franquismo mítico fue concebido en el ámbito de la oposición política la dictadura como un cauce externalizador de los problemas que aquejaban a ese conglomerado de organizaciones y partidos clandestinos en su diversa concepción de la política, la identidad o la soberanía. Fue creado con el fin de que dispares facciones ideológicas y políticas de signo católico, liberal, marxista e incluso revolucionario se arrogaran la identificación exclusiva con un ideal abstracto de libertad y democracia en cuya némesis colocaban a la dictadura. Así, la consideración de algo o alguien como "antifranquista" le concedía automáticamente legitimidad como demócrata, por mucho que el proyecto que reivindicara fuera poco acorde con el de una democracia liberal o "burguesa", como se decía entonces ${ }^{44}$.

En segundo lugar hay que destacar la importancia decisiva que tuvo en Euskadi la aparición de un fenómeno como ETA y el salto que se produjo a partir de finales de los años sesenta. La utilización de la violencia, que en poco tiempo adquirió un carácter claramente terrorista, ha condicionado de forma decisiva la historia de este país y con ello también ha marcado el recuerdo, la construcción y la difusión de una determinada narrativa de aquellos años.

\footnotetext{
43 Véase a este respecto MONTERO, Manuel: “La transición y la autonomía vasca”, en UGARTE, Javier: op. cit.

44 MOLINA, Fernando: "Afinidades electivas. Franquismo e identidad vasca" 1936-1970, en Seminario de Historia. Fundación Ortega y Gasset, curso 2011/12, Documento de trabajo 2012/2, p. 2.
} 
Hay una cuestión fundamental que subyace, tanto en la aparición de ETA como en su historia posterior hasta el final de la dictadura y es precisamente su carácter supuestamente antifranquista; una cuestión que ha servido -y sigue sirviendo- al nacionalismo radical para justificar su historia, no solo hasta el final de la dictadura, sino hasta el mismo momento de la difusión del comunicado de la organización terrorista de octubre de 2011 (36 años después de la muerte de Franco), donde anunció el cese de su actividad.

Ya hace unos cuantos años se publicaron varios estudios que sentaron las bases para comprender y contextualizar las razones que dieron origen a una organización como ETA. El más destacado fue el del profesor Gurutz Jáuregui, donde sostenía que esta organización había surgido gracias al éxito que tuvo en la percepción de un importante sector de la sociedad vasca de la época la idea de la ocupación española de Euskadi; una idea difundida en su momento por Sabino Arana y que el franquismo, con su represión, permitió visualizar hasta constatarla como algo real. La fórmula, como recuerdan en su último trabajo los historiadores Gaizka Fernández y Raúl López, se puede matizar. Sobre todo, apuntan ellos, "porque no reserva un lugar destacado a la voluntad de los militantes de ETA de ponerse en acción. Sin tener en cuenta esta voluntad no se comprende por qué la mayoría de las organizaciones antifranquistas no se sintieron impelidas a matar para defender sus opiniones" 45

No nos extenderemos aquí, por considerarlo innecesario, sobre los argumentos históricos que echan por tierra el despropósito de esa percepción, muy asentada en el nacionalismo vasco y especialmente en el más radical, sobre la ocupación militar de Euskadi. Como recuerdan Fernández y López, el franquismo fue un régimen férreamente dictatorial pero ETA no fue solamente una organización antifranquista sino antiespañola, revolucionaria y abertzale radical y fue antifranquista accidentalmente, como consecuencia de todo lo demás.

Aquella percepción del pasado que influyó en el origen de ETA sirvió para interpretar, por ejemplo, la industrialización como una explotación económica de España hacia Euskadi, obviando de paso que ésta, si es la que hubo, se produjo con la inestimable ayuda de las élites locales. Los jóvenes que se incorporaron a ETA en sus diferentes ramas durante los años sesenta se vieron influidos por varias de las grandes ideologías de la época: el nacionalismo radical, el marxismo-leninismo, el maoísmo, el trotskismo y hasta diversas formas libertarias. Y todas ellas se basaban en políticas de identidad, en planteamientos maximalistas y excluyentes que sirvieron en su momento para suministrar unas respuestas sencillas a problemas sumamente complejos $^{46}$.

45 FERNANDEZ SOLDEVILLA, Gaizka y LÓPEZ, Raúl: p. 332. Hace ya algunos años otros autores, como GARMENDIA, José María: Historia de ETA. Aramburu editorial, San Sebastián, 1995, p. 41. ya hicieron una reflexión, similar, aunque algo menos elaborada. A raíz de la reedición de su libro el profesor Garmendia, apuntó lo siguiente: "La verdad es que durante cierto tiempo he pensado que esta tesis (la que defiende Jáuregui) era reduccionista porque olvidaba a mi entender los componentes antifranquistas de muchos militantes de la organización. Vistas las cosas desde hoy mi colega Jáuregui tenía toda la razón. Si ETA se mantiene es porque siempre ha sido una organización nacionalista, no antifranquista, sino antiespañola, independientemente del sentir de algunos de sus militantes o, incluso, de dirigentes"

46 FERNÁNDEZ, Gaizka y LÓPEZ ROMO, Raúl: Sangre, votos, manifestaciones... op. cit. 
Un elemento común a todas esas ideologías fue también la creencia ciega en una especie de "filosofía de la acción" y en ese sentido la aparición del fenómeno de ETA no fue algo excepcional, ni siquiera en el recurso a la violencia como medio para conseguir la liberación nacional y social de Euskadi. El recrudecimiento de la violencia terrorista, y especialmente de la encarnada por ETA, a lo largo del proceso de institucionalización del régimen democrático fue el problema fundamental que lastró el vertiginoso viaje que se produjo desde el franquismo hasta la democracia. Y este viaje tuvo un coste enorme humano y político, determinante en el futuro del País Vasco.

El final de la dictadura con su terrible represión convirtió a ETA en un referente político, simbólico y emocional para toda una serie de grupos vinculados de un modo u otro a partidos pero también a organizaciones de los movimientos sociales, sindicales, culturales y a favor de la euskaldunización de la órbita del nacionalismo vasco radical, consiguiendo que asumieran en mayor o menor medida determinados símbolos, planteamientos ideológicos y políticos ${ }^{47}$. La denominada "cuestión nacional" se convirtió de este modo en un banderín de enganche para todas las organizaciones abertzales y para buena parte de las organizaciones de la izquierda, desde el PSOE hasta los partidos más extremistas. Pero el elemento crucial fue, sobre todo, la interiorización por parte de un sector importante de la sociedad vasca de la legitimidad del uso de la violencia y más en concreto, del terrorismo. En torno al nacionalismo radical se fue extendiendo una tupida red de complicidades con la violencia terrorista que poco tenía ya que ver con la solidaridad son los represaliados que habían mostrado muchos militantes antifranquistas durante la dictadura. En este contexto, la muerte de un numeroso grupo de miembros de ETA en diversos enfrentamientos u operativos montados por las Fuerzas del Orden Público contribuyó aún más a reforzar la imagen heroica y comprometida de la militancia de ETA dentro de ese mismo sector social. Su figura fue elevada a la categoría mártires, como ya ocurrió en 1968 con Txabi Etxebarrieta y como pasaría 10 años más tarde con José Miguel Beñarán, Argala, asesinado por el Batallón Vasco Español ${ }^{48}$.

En estas circunstancias la brutal respuesta del Estado frente a ETA, y contra todos aquellos que fueran sospechosos de mantener alguna relación con esta organización, jugó un papel decisivo. La irrupción de toda una serie de bandas terroristas de extrema derecha -muchas de ellas ligadas de un modo u otro a los aparatos del Estadocontribuyó a extender el terror en las calles y pueblos del País Vasco durante aquellos años. Esta situación se vio además agravada por una acción represiva en muchos casos desproporcionada e indiscriminada por parte de unas Fuerzas de Seguridad del Estado ${ }^{49}$. Todo ello contribuyó indudablemente a profundizar en un proceso de deslegitimación del régimen democrático entre amplias capas sociales dentro del País Vasco, que percibieron estas acciones como la continuidad de las desarrolladas por la policía durante los últimos años de la dictadura franquista. Este proceso fue confor-

47 Ibídem op. cit.

48 Sobre el proceso martiriológico del abertzalismo radical véanse entre otros CASQUETE, Jesús: En el nombre de Euskal Herria. La religión politica del nacionalismo vasco radical. Madrid, Tecnos, 2009 y Casquete, Jesús: "Agitando emociones. La apoteosis del héroe-mártir en el nacionalismo radical”, en Bakeaz, no 81. http://ehu.academia.edu/JesusCasquete/Papers/953596/Agitando_Emociones

49 REINARES, Fernando: Terrorismo y Antiterrorismo, Barcelona, Ediciones Paidós, 1998, p. 168. 
mando una auténtica "comunidad de violencia" en torno a ETA y su brazo político, Herri Batasuna, imprescindible para comprender la intensificación y persistencia del fenómeno terrorista en el País Vasco y algunos de los comportamientos sociales que se produjeron durante aquella época.

Como consecuencia de ello la transición política en el País Vasco no fue sólo especialmente dramática ${ }^{50}$; careció también del factor legitimador que definió a este proceso en el resto de España y produjo una enorme brecha en el interior de la sociedad vasca. Como ha afirmado el profesor Luis Castells, en el País Vasco “....resultó imposible llegar a consensos sobre valores básicos con un sector de la ciudadanía vasca, de forma que Euskadi se va a revelar como una comunidad invertebrada, en la que un colectivo minoritario pero numeroso rechazaba el sistema democrático y con el que resultaba imposible establecer canales de comunicación" ${ }^{51}$.

En tercer lugar, hay una cuestión fundamental a la hora de analizar y valorar la importancia que tuvo el antifranquismo en el País Vasco. Hace algunos años el exministro del Interior Jaime Mayor Oreja hizo unas declaraciones que provocaron un enorme revuelo en las que afirmaba sobre el franquismo: "Muchas familias lo vivieron con naturalidad", "era una situación de extraordinaria placidez" 52 . Más allá del juicio moral -e incluso político- que merezcan estas palabras, pronunciadas por un antiguo ministro de un gobierno democrático en un país que suportó durante cuarenta años la existencia de una dictadura como la franquista, aquellas declaraciones merecen alguna reflexión desde el punto de vista de quienes nos dedicamos a la historia de este periodo. Y la merecen por una sencilla razón; porque reflejan la opinión de un sector muy importante de la sociedad que vivió, efectivamente, con naturalidad e incluso con placidez aquella época. Y esta consideración no solo es aplicable a aquellos que compartían el ideario o simplemente los intereses del régimen; en nuestra opinión también es extensible a millones de personas que tras superar los duros años de la posguerra se dedicaron básicamente a trabajar, a ahorrar, a conseguir una vivienda y alcanzar un nivel de vida que se vio favorecido por la nueva política económica que impulsó el régimen de Franco a finales de los años cincuenta ${ }^{53}$. En definitiva, se dedicaron a poner en marcha sus propios proyectos de vida sin cuestionar ni la naturaleza ni los métodos del régimen, ni mucho menos oponerse activamente al mismo. Y ello también es aplicable al País Vasco donde, a pesar de toda esta acti-

50 Véanse, entre otros, CARNICERO, Carlos y PÉREZ, José Antonio: "La radicalización de la violencia terrorista durante la transición en el País Vasco: los años de plomo", Historia del Presente, n 12. 2008, pp. 111-128.

51 CASTELLS ARTECHE, Luis: "El nacimiento de Euskadi”, en VVAA. Transición y democracia en Euskadi. Texto original inédito.

52 http://elpais.com/diario/2007/10/16/espana/1192485613_850215.html

53 Existen ya una serie de trabajos sobre esta cuestión para èl resto de España, como los de SEVILLANO CALERO, F.: "Consenso y violencia en el "nuevo Estado franquista": historia de las actitudes cotidianas", en Historia Social, n 46, 2003, pp. 159-171; CAZORLA SÁNCHEZ, A.: "Sobre el primer franquismo y la extensión de su apoyo popular", Historia y Política, 8, 2002, pp. 303-320; MOLINERO, C.: La captación de las masas. Política social y propaganda en el régimen franquista, Madrid, Cátedra, 2005. Sin embargo, para el País Vasco solo disponemos de algunos, muy pocos trabajos: CALVO VICENTE, C.: Poder y consenso en Guipúzcoa durante el primer franquismo, 1936-1951, tesis doctoral inédita, Salamanca, Universidad de Salamanca, 1994 y en cierto modo el estudio de CANALES, Francisco A.: Las otras derechas. Derechas y poder local en el País Vasco y Cataluña en el siglo XX, Madrid, Marcial Pons, 2009. 
vidad anteriormente señalada como sobre todo se desató a partir de los años sesenta y se radicalizó en el tramo final del régimen, la oposición organizada fue realmente minoritaria. La imagen heroica de un pueblo vasco levantado prácticamente en armas contra el franquismo forma parte de la propia mitología que sobre esta cuestión ha difundido el nacionalismo, pero también un sector nada despreciable de la izquierda.

Por último habría que apuntar la importancia que tuvo en este proceso la irrupción desde los primeros momentos de la transición de dos fuerzas como el PNV y el PSOE, que no fueron -salvo excepciones puntuales- las organizaciones más activas en la lucha antifranquista. Las primeras elecciones en el País Vasco favorecieron a las formaciones históricas más moderadas y dejaron patente la importancia que aún tenía la memoria de la guerra entre las nuevas generaciones que no habían vivido aquella época. Frente a la sorprendente irrupción de estos partidos otras formaciones políticas como el PCE-EPK, que habían soportado el peso de aquellas luchas, no vieron recompensados en votos su entrega en favor de las libertades democráticas durante la dictadura $^{54}$. Todas estas circunstancias facilitaron la elaboración y difusión por parte del nacionalismo, que permaneció en el poder durante treinta años, de un discurso donde la oposición antifranquista no nacionalista quedó prácticamente borrada en pocos años de la memoria colectiva del antifranquismo, como si hubiera sido ajena por completo a la propia historia del país.

\section{La importancia del relato histórico antifranquista para el nacionalismo radical}

Todo ello ha derivado en un relato mítico sobre el franquismo, el antifranquismo y la represión en el País Vasco que ha sido difundido con un extraordinario éxito por el nacionalismo; por todo el nacionalismo, aunque con matices que es necesario destacar ${ }^{55}$. Mientras el PNV desde el final de la dictadura ha seguido alimentado un recuerdo del franquismo que hunde sus raíces en la propia concepción de la guerra civil como guerra de ocupación y se presenta ante la sociedad vasca como el genuino y prácticamente único representante de la continuidad del Gobierno Vasco durante cuarenta años de dictadura; es decir, el partido que consiguió en "dura pugna con Madrid" arrancar, como si se tratase de una victoria militar, la consecución del nuevo estatuto de 1979, el nacionalismo radical se planteó una estrategia diferente que ha demostrado sobradamente su éxito.

Como ha analizado el profesor Jesús Casquete, el abertzalismo radical se fue apropiando de los símbolos tanto del nacionalismo tradicional (PNV) como del hetero-

54 Véase a este respecto la enorme decepción para cuantos lo vivieron en el seno del EPK, provocaron los resultados de las primeras elecciones legislativas, en IBÁÑEZ ORTEGA, Norberto y PÉREZ PÉREZ, José Antonio: Ramón Ormazabal. Biografía de un comunista vasco... op. cit.

55 De este modo, como ha apuntado MOLINA, Fernando: op. cit. p. 6, "Los nacionalistas vascos, fusilados, exiliados o silenciados, se convierten en "el paradigma de los vencidos, ya que perdieron la lucha (por la República) y además perdieron su libertad política y cultural, con la prohibición de hablar euskera”. Esta lectura se hace, además, como ha apuntado Paloma Aguilar, adaptando la represión de la guerra y la posguerra, lejana en el recuerdo, a la de los últimos años de la dictadura y la represión.. Véase AGUILAR, Paloma: «La guerra civil española en el discurso nacionalista vasco. Memorias peculiares, lecciones diferentes», UGARTE, Javier (ed.), La transición en el País Vasco y España... op. cit. pp. 121-154. 
doxo de los años treinta (ANV), mediante el "vampirismo simbólico" y la manipulación de la historia reciente del País Vasco ${ }^{56}$. Para desgracia del PNV, el discurso del abertzalismo radical y la construcción de un determinado relato histórico se vio favorecido por el liderazgo mesiánico de algunos de sus más destacados oradores y publicistas como Telesforo Monzón, veterano jeltzale reconvertido en guía del abertzalismo radical durante los primeros años de la transición, capaz de santificar a los miembros de ETA de los años setenta y ochenta como los legítimos herederos de los gudaris de la guerra civil. Un discurso que ha perdurado prácticamente hasta hoy en día, que ha servido para justificar los actos de ETA durante las últimas cuatro décadas y que probablemente sirva incluso durante los próximos años, con las oportunas matizaciones, para encontrar acomodo entre las nuevas generaciones de la mano de formaciones como Bildu, Amaiur, y finalmente, Sortu.

Frente a ambos discursos, que en realidad y con matices pueden ser simplemente la versión moderada y radical del mismo argumento y encarnan con éxito un peculiar proceso de patrimonilización de la historia a partir de una determinada visión del pasado, la izquierda no nacionalista en el País Vasco ha sido incapaz - o ha renunciadoa articular y difundir un discurso legitimador basado en protagonismo que tuvo en las lucha antifranquista y en la defensa de las libertades democráticas. Paradójicamente -o quizás no tanto- muchos de aquellos que protagonizaron las luchas antifranquistas en las filas de izquierda y más concretamente en las del PCE-EPK, desde las CCOO de Euskadi e incluso desde los sectores más izquierdistas y menos nacionalistas de ETA, fueron algunos de los que de forma más temprana se posicionaron públicamente contra el terrorismo abertzale, protagonizando las primeras manifestaciones contra esta organización ${ }^{57}$. Su presencia no pasó desapercibida para ésta última, ni durante la transición ni veinte años más tarde, cuando a finales de los años noventa aquellos veteranos militantes antifranquistas volvieron a las calles a reivindicar las libertades democráticas frente al totalitarismo que representaba ETA, alimentada por la complicidad de su entorno. Los asesinatos de José Luis López de la Calle y Juan María Jáuregui revelaron la escasa importancia que para ETA representaba el pasado antifranquista de ambos. Su posicionamiento público contra el terrorismo e incluso el hecho de que el segundo de ellos hubiera sido Gobernador Civil de Gipuzkoa entre 1994 y 1996, a pesar de haber militado en el frente cultural de ETA durante los años sesenta, les situaba fuera de la comunidad nacionalista y al lado del enemigo español. Algo muy similar ocurrió incluso con quienes habían sido juzgados y condenados a muerte en el juicio de Burgos, como Mario Onaindía o Teo Uriarte. Veinte años después de aquellos acontecimientos, que les convirtieron en dos símbolos, especialmente en el caso del primero por su encendida intervención en el juicio militar, su pasado antifranquista apenas constituía un episodio pasajero y efímero, una pequeña

56 Véase a este respecto CASQUETE, Jesús: En el nombre de Euskal Herria ... op. cit.

57 Ramón Ormazabal, secretario general de los comunistas vascos, torturado tras su detención en 1962 fue uno de los primeros políticos que procedían de la oposición antifranquista que se posicionaron contra la violencia terrorista de ETA. Véase a este respecto IBAÑEZ ORTEGA, Norberto y PÉREZ PÉREZ, José Antonio: Ramón Ormazabal... op. cit. Las movilizaciones convocadas por el EPK contra ETA durante los primeros años de la transición se desarrollaron en medio de una soledad que para muchos de ellos recordaba a la soledad de las luchas antifranquistas. 
impostura personal para el abertzalismo más radical, frente a la entrega de aquellos que habían seguido "coherentemente" sosteniendo las armas y manteniendo con ello viva la lucha de $\mathrm{ETA}^{58}$.

La participación activa de la izquierda no nacionalista en las luchas antifranquistas en el País Vasco resultaba incómoda al nacionalismo porque rompía con la tradicional discurso basado en la concepción de la guerra civil como guerra de ocupación española. Para seguir alimentado ese discurso sigue siendo necesaria la producción de un revisionismo histórico que se ve alentado por el final de la violencia de ETA. La derrota del terrorismo ha obligado al entorno político y social que lo sustentó durante décadas a abrir en un nuevo frente: el de la memoria y la narrativa de los últimos cincuenta años de nuestra reciente historia. Se trata de una nueva vuelta de tuerca en el proyecto de nacionalización de la memoria antifranquista. Y ello, evidentemente, incluye toda una batería de iniciativas de carácter pseudohistórico encaminadas a "explicar" el origen, desarrollo y final de ETA desde el franquismo hasta nuestros días. Títulos tan significativos como El franquismo en Euskal Herria: la solución final o No les bastó Gernika constituyen solo dos ejemplos de esta nueva hornada de trabajos ${ }^{59}$. En argumento y la cronología de ambos trabajos resulta bien ilustrativo sobre los objetivos finales que se proponen. En el primero de ellos el propio título ya induce a ello: la existencia de una estrategia genocida encaminada al exterminio del pueblo vasco por parte del régimen franquista. Por su parte, el en el segundo trabajo, este genocidio supondría en la práctica la continuidad de una estrategia que arrancó con el bombardeo de Gernika en 1937 y siguió nada más y nada menos que hasta el año... 2010 (sic). Ambos trabajos han sido impulsados por la Fundación Euskal Memoria, una iniciativa que a través de diversos grupos de trabajo formados en todos los pueblos del País Vasco, está haciendo una relectura de la guerra civil, el franquismo y la represión que se llevó a cabo durante aquella época ${ }^{60}$.

Como es de imaginar, esta visión maniquea del pasado dibuja el franquismo como una régimen que prácticamente careció de bases sociales y políticas en el País Vasco, es decir, como una dictadura sostenida durante cuarenta años por un enemigo exterior, el español, sin sopesar ni como hipótesis la posibilidad de que este régimen hubiera podido a lo largo de todo ese tiempo, no ya contar con un importante sector que colaboró activamente con el franquismo, sino simplemente lograr un determinado consenso social que explicase, como en el resto de España, su enorme longevidad.

Esa es la cuestión fundamental, el último reto de la izquierda abertzale: ganar la batalla en el combate por la memoria; la última, la definitiva, la más importante. Ganar esa batalla se ha convertido en una verdadera obsesión para quienes justificaron o apoyaron el terrorismo, porque nadie quiere pasar a la historia como un asesino o

58 Una reflexión sobre este proceso en las biografías de ambos: URIARTE, Teo: Mirando atrás. Del Proceso de Burgos a la amenaza permanente. Barcelona, Ediciones B, 2005, ONAINDIA, Mario: El precio de la libertad. Memorias (1948-1977). Madrid, España hoy-Espasa Calpe, 2001 y ONAINDIA, Mario: El aventurero cuerdo. Memorias (1977-1981). Madrid, España hoy-Espasa Calpe, 2004.

59 EGAÑA, Iñaki: El franquismo en Euskal Herria: la solución final, Euskal Memoria Fundazioa, 2011. AGUIRRE, Joxean: No les bastó Gernika, Andonain, Euskal Memoria Fundazioa, 2011.

60 Un análisis exhaustivo de este relato histórico en CASTELLS, Luis y MOLINA APARICIO, Fernando: "El relato del pasado en la Euskadi reciente", en Ayer, n 89, 2013, pp. 215-227. 
como un colaborador imprescindible en la comisión de aquellos crímenes. Para ello era preciso, sigue siéndolo, crear un relato que demuestre que todo aquel horror fue a la vez inevitable y necesario, y que fue, en todo caso, una respuesta minúscula comparada con la enorme maquinaria criminal que desde el principio de los tiempos desplegó España contra el pueblo vasco ${ }^{61}$. No se trata, evidentemente de ninguna novedad en el relato, ni de alterar en lo más mínimo la tradicional versión de la historia que ha defendido y de la que se ha alimentado el nacionalismo radical ${ }^{62}$; pero el argumento adquiere ahora, con la derrota policial y judicial de ETA, una nueva dimensión, un nuevo significado que busca al menos dar un sentido a esa lucha y que consiste básicamente en reivindicar su memoria como una aportación decisiva e imprescindible que creó la situación necesaria para justificar su tardía apuesta por las "vías políticas y democráticas".

${ }^{61}$ Uno de los tres portavoces de Sortu, Xabi Larralde, acudió en abril de 2013 a testificar a petición de la defensa de los acusados en el juicio que se celebra en Francia por el asesinato a sangre fría de dos guardias civiles en la localidad de Capbreton a manos de ETA. En su testimonio recordó que aquellos asesinatos "se inscriben en un conflicto armado de origen político" y apuntó que "desde mediados del siglo XIX hasta ahora no ha habido una generación de jóvenes vascos que no haya tomado las armas para defender derechos que les parecían legítimos", haciendo suyos los argumentos de ETA defendidos en los últimos comunicados para justificar su historia y su final. El Correo, 16 de abril de 2013.

62 Véase a este respecto la utilización y manipulación de toda una serie de recursos simbólicos -que incluso han sido vampirizados del nacionalismo tradicional- para elaborar su propio relato histórico, como se analiza profusamente en CASQUETE, J.: En el nombre de Euskal Herria ... op. cit. Véase también sobre este tema FERNÁNDEZ, Gaizka: Héroes, heterodoxos y traidores... op. cit. p. 73 y ss. 